\title{
Twitter como herramienta para la comunicación en salud en el contexto del fomento de la donación de órganos en el Perú
}

\author{
Twitter, osasunari buruzko komunikaziorako tresna, \\ Perun organo-emateak sustatzeko testuinguruan
}

\section{Twitter as a tool for health communication in the context of promoting organ donation in Peru}

\section{Maria Antonia Strauck Franco ${ }^{1}$ Claudia Alexandra Guillén Arruda²}

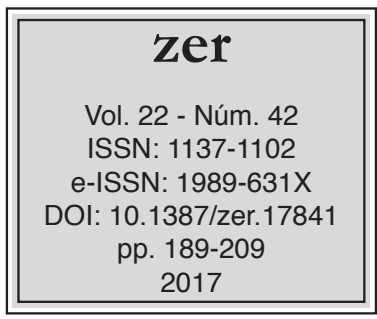

Recibido el 5 de enero de 2017, aceptado el 20 de marzo de 2017.

\section{Resumen}

Este artículo analiza las características de la comunicación a través de Twitter en el marco del fomento de la donación de órganos, a partir del estudio de lo publicado por el Ministerio de Salud (Minsa) y el Seguro Social de Salud (EsSalud) en el Perú y de las respuestas de los usuarios ante estos mensajes, donde se pudo evidenciar que esta red social, por sus particularidades específicas y recursos disponibles, que permiten una retroalimentación continua, es una herramienta valiosa en el contexto del desarrollo de iniciativas de comunicación en salud.

Palabras clave: Comunicación en salud, comunicación 2.0, redes sociales, Twitter.

\section{Laburpena}

Artikulu honetan, organo-emateak bultzatzeko Twitter bidez egiten diren komunikazioen ezaugarriak aztertzen dira, Peruko Osasun Ministerioak (Minsa) eta Osasunaren Gizarte Segurantzak (EsSalud) argitaratutakoetan eta erabiltzaileek Twitterreko mezuei emandako erantzunetan oinarriturik. Argi geratu da sare sozial hori balio handiko tresna dela osasun arloko komunikazioko ekinbideak bultzatzeko, etengabeko berrelikadurarako bidea ematen duten zenbait berezitasun eta baliabide baititu.

Gako-hitzak: Osasun arloko komunikazioa, 2.0 komunikazioa, sare sozialak, Twitter.

\footnotetext{
Universidad Peruana de Ciencias Aplicadas, pcimmstr@upc.edu.pe

2 Universidad Peruana de Ciencias Aplicadas, claudia.guillen@upc.edu.pe
} 


\begin{abstract}
This article analyzes the characteristics of the communication through Twitter in the framework of the promotion of organ donation, based on the study of the publications of the Ministry of Health (Minsa) and Social Health Insurance (EsSalud) in Peru and on the responses of users to these messages, where it was possible to show that this social network, due to its specific peculiarities and available resources, which allow continuous feedback, is a valuable tool in the context of the development of health communication initiatives.
\end{abstract}

Keywords: Health Communication, 2.0 communication, social networks, Twitter. 


\section{Introducción}

La donación de órganos es un acto en el cual una persona de manera altruista declara en vida la voluntad de ceder sus órganos a otra, para que esta pueda seguir viviendo, se pueden donar corazón, hígado, riñones, pulmones, páncreas y también tejidos (Organización Nacional de Trasplantes, s.f.), por tanto, los órganos de un solo donante pueden beneficiar hasta a ocho personas que lo necesiten. En el Perú existe un bajo índice de donantes de órganos, esta situación se traduce en las largas listas de espera de pacientes que necesitan un trasplante, y que en 2016 ascendía a 1.251 personas (Minsa, 2016).

En el año 2015 el porcentaje de donación y trasplante de órganos en Perú fue de 2,6 por cada millón de habitantes, lo que lo coloca muy lejos de países como España, líder en donación y trasplante a nivel mundial, donde en el mismo año la tasa fue de 40,2 por cada millón de habitantes, o del país líder en América Latina, Argentina, con una tasa de 13,6 donantes por cada millón de habitantes en 2015 (Council of Europe y Organización Nacional de Trasplantes, 2016: 38, 41, 42). Además, esta cifra se ha reducido en los últimos años: 3,2 en 2010, 4,3 en 2011, 3,2 en 2012 y 2013 y 2,4 en 2014.

La donación y trasplante de órganos es un proceso en donde se implican diversos aspectos, y existen varios factores que afectan al aumento o disminución en la tasa de donantes y trasplantados, uno de ellos es la negativa de los familiares con respecto a que un miembro de su familia se convierta en donante de órganos. Tal es así que, en el Perú, a diciembre de 2015, el porcentaje de familiares que se negaban a la donación ascendía al 67,1\%. A lo largo del tiempo esta tendencia evolucionó favorablemente, si se consideran las cifras de años anteriores, pero aún está muy lejos de llegar al nivel de otros países líderes en donación y trasplante de órganos y tejidos, como es el caso de Uruguay, en el escenario americano, donde en el mismo año el porcentaje de negativas fue de $0 \%$ (Council of Europe y Organización Nacional de Trasplantes, 2016: 50). En 2011 la negativa de los familiares era de un 49\%, en 2012 de un 61,3\%, en 2013 de un 63,3\% y en 2014 de un 62,2\%.

Entre los factores que condicionan la donación de órganos en el Perú se encuentran también las creencias y mitos con respecto a esta práctica, con los cuales se enfrentan día a día las instituciones de salud a la hora de gestionar las donaciones, y que a su vez se resaltaron en un estudio de opinión realizado en 2009 por The Lima Consulting Group, a pedido del Minsa.

Las principales creencias sobre la donación de órganos en el Perú, según el estudio mencionado son: 1. la existencia de secuestros de niños para robar sus órganos, 2. que por el hecho de que alguien indique que es donante de órganos en el Documento Nacional de Identidad (DNI), lo podrían "matar a propósito" para robarle sus órganos, 3. el tráfico de órganos, 4. que en los hospitales roban órganos, 5 . diversas creencias religiosas sobre el alma y el cuerpo después del fallecimiento (The Lima Consulting Group, 2009: 14). Sobre el secuestro de niños, que es la creencia más mencionada en el estudio, cabe resaltar que es un tema que, según Matesanz (1994: 640), está muy arraigado en todas las culturas, pero que cobra mucha importancia en la peruana, ya que su origen se remonta a leyendas nacidas incluso en el periodo pre incaico. 
En el marco de este escenario se encuentra la Organización Nacional de Donación y Trasplante (ONDT), creada en el año 2006, que se convierte en la entidad encargada de promocionar todos los temas relacionados a la donación de órganos y tejidos, la cual depende del Minsa y cuenta con representantes en EsSalud, en el Ministerio del Interior, en el Ministerio de Defensa y en la Asociación de Clínicas Particulares (Organización Nacional de Donación y trasplante, s.f.).

Para la regulación de la donación de órganos en el Perú existe un conjunto de leyes, entre las que se destacan la Ley No 28189 "Ley General de Donación y Trasplante de Órganos y/o Tejidos Humanos" (Congreso de la República del Perú, 2004) y la Ley N ${ }^{0} 29471$ "Ley que promueve la obtención, la donación y el trasplante de órganos o tejidos humanos" (Congreso de la República del Perú, 2009), la primera se encarga de establecer los parámetros de todo el proceso de donación, indicando los alcances y limitaciones, y la segunda busca establecer directrices para la promoción de la donación de órganos.

En 2016 se promulga también la Ley $N^{\circ}$ 30473, que modifica artículos de la antes mencionada Ley 29471, y que establece que la decisión de ser donantes de órganos que es consignada a través de una declaración jurada en el Registro Nacional de Identificación y Estado Civil (RENIEC) o por medio de la suscripción del acta de consentimiento voluntario, solo puede ser revocada por el propio donante y no por terceros (Congreso de la República del Perú, 2016).

Sobre esto último, según cifras del año 2014, el 77,65\% de los peruanos consigna su negativa de ser donante de órganos en su DNI y solo un $13,1 \%$ indica su deseo de ser donante en este documento (Neciosup, 2014: 7) y a 2015 más de 100 mil personas ya habían firmado el acta de consentimiento voluntario para ser donantes (Minsa, 2015).

Se consideró importante estudiar cómo es la comunicación del Minsa con respecto al tema de la donación de órganos, ya que es la entidad más importante en términos de salud, siendo la institución que propone los lineamientos sobre políticas sanitarias en el Perú, además, la Organización Nacional de Donación y Trasplante (ONDT), depende de esta institución ejecutiva. EsSalud por su parte es estudiada por ser un organismo público cuya finalidad radica en cubrir a los trabajadores activos y formales y a sus derechohabientes ${ }^{3}$, otorgando prestaciones sociales, económicas y de prevención en Salud (EsSalud, s.f.), es decir que todos los trabajadores formales en el territorio peruano tienen cobertura de esta entidad. La oficina encargada de informar, difundir y procurar la donación de órganos en esta institución es la Gerencia de Procura y Trasplante.

\section{La comunicación en salud}

Según el contexto presentado, se entiende a la donación de órganos y la consecuencia de este acto, los trasplantes, como importantes temas de salud para ser abordados desde la comunicación. En este sentido, uno de los primeros puntos que se deben aclarar es que la comunicación en torno a temas e instituciones de salud recibe varios nombres en español (comunicación y salud, comunicación para la salud o comunicación en salud), mientras que en inglés se emplean los términos

Personas que derivan sus derechos de los trabajadores formales. 
"health communication", así que indagando en las diversas propuestas es importante comenzar por definir lo que para fines de este estudio es la comunicación en salud y cuál es su alcance.

Para Ratzan, Stearns, Payne, Amato y Liebergott, la comunicación en salud puede ser definida como "the art and technique of informing, influencing, and motivating individual, institutional, and public audiences about important health issues" (1994: 362), mientras que Nutbeam (1998: 18) la conceptualiza como:

una estrategia clave destinada a informar a la población sobre aspectos concernientes a la salud y a mantener cuestiones sanitarias importantes en la agenda pública. El uso de los medios informativos y los multimedia, además de otras innovaciones tecnológicas para difundir información sobre salud entre la población, aumenta la concienciación sobre aspectos específicos de la salud individual y colectiva y sobre la importancia de la salud en el desarrollo.

Todas las acepciones anteriores se centran en definir la comunicación en salud desde la perspectiva de las organizaciones sanitarias, mientras que Berry (2006: 2) va más allá y la define como aquella que engloba a toda comunicación humana que se relaciona con la salud, ampliando su alcance a cualquier contexto en el que se traten temas de salud, es así que teniendo en cuenta que esta no puede centrarse únicamente en una parte del proceso, Renata Schiavo (2007: 4), por su parte, explica que debe ser entendida desde el significado literal de la comunicación, es decir, como un intercambio de información de ida y vuelta a través de un sistema común de signos, que propicie entendimiento mutuo a través de diversos medios, en relación a temas de salud. La autora explica que el objetivo de esta comunicación es mejorar la salud de los individuos y las comunidades a través de la transmisión de información relacionada a la misma, para influir en las decisiones de estos, en lo que respecta a su salud (Schiavo, 2007: 5).

En lo planteado por Schiavo se mencionan varios aspectos importantes, como el carácter bidireccional y también el persuasivo de la comunicación en salud, considerando su principal objetivo, que es el de influir en el comportamiento de las personas con respecto a la salud. Es así que esta comunicación se desarrolla desde diferentes dimensiones y se investiga desde perspectivas tales como la comunicación intercultural, la relación médico-paciente, las actitudes de las personas respecto a temas de salud, el rol de los medios de comunicación y de las nuevas tecnologías en la construcción de mensajes, las campañas informativas y de promoción sobre temas de salud, y también la gestión de las organizaciones de salud y en el flujo de comunicación en las mismas (Wright, Sparks y O’Hair, 2013).

Si nos situamos en el escenario latinoamericano, el desarrollo de esta área de especialización también depende de la introducción de la especialidad en las escuelas de comunicación (Alcalay, 1999: 195) y del énfasis en la investigación que permita adoptar e implementar medidas que influyan positivamente en la salud de la población.

Por tanto, la comunicación en salud es un área interdisciplinar y aplicada que permite a las ciencias de la comunicación realizar un aporte para mejorar y lograr el 
cambio positivo que se requiere a través de modelos de acción (Alcalay, 1999: 195) y depende en gran medida de la importancia que se le dé la investigación de campo, ya que de esto depende también el desarrollo de políticas y prácticas que ayuden a lograr un cambio positivo en la sociedad (Kreps 2012: 496).

En el contexto de la comunicación en salud existen a su vez diversas teorías, entre las que se encuentran el modelo de creencias en salud, el modelo de las etapas de cambio, la teoría de la acción razonada, la teoría del riesgo y la teoría de la gestión del miedo (Cuesta, Menéndez y García, 2008; Schiavo, 2007), entre otras, que plantean abordar esta comunicación desde distintas perspectivas, pero tienen en común el tratar de identificar la mejor manera para lograr influir en el comportamiento de las personas con respecto a temas de salud.

\section{Comunicación en salud a través de las redes sociales}

Las redes sociales en el escenario de la comunicación en salud se encuadran en lo que vendría a ser la E-Salud y la Salud 2.0, que son dos maneras de referirse a las actividades relacionadas a la salud, desarrolladas en el universo de Internet. Sobre el primer término, la Organización Mundial de la Salud (2005: 115), explica que toda actividad realizada en el contexto de la salud con o a través de las Tecnologías de la Información y la Comunicación (TICs), se incluye en el campo de acción de la cibersalud o E-Salud. Del mismo modo, Neuhauser y Kreps (2010: 14), indican que $E$-Salud (en inglés "eHealth"), es un término que abarca varias disciplinas que tienen que ver con las tecnologías de la información y la comunicación (TICs) en el ámbito de la salud.

Tratar el tema de la E-Salud y el rol de las TICs en este ámbito implica, como ya se explicó, hablar de la salud 2.0. Este término proviene de la adaptación de "Web 2.0", término empleado por Tim O'Reilly (2005) que en resumen define a la web evolucionada, caracterizada por el empoderamiento del usuario, por la interactividad y por aplicaciones que posibilitan la construcción colectiva de conocimiento a partir de la participación colaborativa. En este sentido, Caballero Uribe (2011: viii) define la Salud 2.0 como el uso de diversas herramientas en el entorno de la web 2.0, por parte del personal de salud y pacientes, que se caracteriza por emplear los principios de la web abierta y colaborativa y las redes, con el fin de "personalizar el cuidado de la salud, colaborar y promover educación en salud".

Es así que, la comunicación en salud en el escenario web se caracteriza por ser personal y contextual, es decir, las actuales herramientas y aplicaciones disponibles permiten establecer una comunicación directa con las audiencias específicas, adaptándose a su contexto a través de la personalización de la información que permite la web semántica. Así también los usuarios se convierten en co-creadores de contenido y en el escenario de la salud, las personas interesadas o con necesidad de información sobre temas de esta índole pueden encontrar contenido adaptado a sus preferencias y necesidades (Kotskova, 2015: 111; Neuhauser y Kreps, 2010: 15-16).

En el Perú, según cifras oficiales, hasta el año 2014, el $40 \%$ de la población tenía acceso a internet, esto representa a 12 millones de personas aproximadamente (Instituto Nacional de Estadística e Informática, 2014). 
En este escenario digital, se encuentra Twitter, que es una de las redes sociales más importantes en el mundo, con 319 millones de usuarios activos en 2016 a nivel global (Twitter Investor Relations, 2017: 3), y la segunda con más cantidad de usuarios en el Perú, llegando a tener 4,3 millones en 2015 y siendo la estimación para 2016 de que finalmente se llegue a 6 millones de usuarios (Quantico Trends, 2016).

Sobre el binomio Twitter y salud se han realizado varios estudios, entre los que se resaltan algunos como el análisis de cómo se diseminó la información sobre la pandemia de la gripe H1N1 en 2009 a través de esta red social (Chew y Eysenbach, 2010), también otro estudio sobre la identificación de malentendidos con respecto al uso de antibióticos a través de los tweets (Scanfeld, Scanfeld y Larson, 2010), otra investigación donde se propone identificar brotes de influenza a través de los mensajes de Twitter (Culotta, 2010), e incluso un estudio que analiza la relación entre las expresiones de alegría en Twitter y la obesidad, la dieta y la actividad física (Gore, Diallo y Padilla, 2015), y en el escenario peruano se puede encontrar el aporte de Curioso y Carnero (2011), con el estudio sobre Twitter como herramienta para la promoción de la investigación en salud.

El motivo por el cual Twitter es considerada una herramienta útil en el contexto de la comunicación en salud radica en que a través de los mensajes de los usuarios se pueden medir características, así como testear mensajes y obtener feedback, y a raíz de ello tomar medidas sanitarias (Paul y Dretze, 2011: 265; Kotskova, 2015: 111; Manchetti, 2009), además, esta red social puede fomentar conversaciones sobre temas de salud, para concienciar y para llamar a la acción (Manchetti, 2009).

Para comunicar en Twitter es importante considerar aspectos basados en sus características, y en el contexto de otro tipo de organizaciones, varios autores mencionan algunos puntos clave que se deben tener en cuenta y que bien se pueden aplicar a las organizaciones de salud, como son la escucha, el valor agregado a partir de la publicación de información útil y de contenido multimedia significativo, el compartir el contenido de otros y el contestar a los que responden, además de la utilización de hashtags efectivos y creativos (Herrera y Requejo, 2012: 82-91).

Pero ya incursionando específicamente en la manera en que se debería abordar la comunicación sobre temas de salud en esta red social, se destacan varios factores a considerar, algunos ya mencionados más arriba, pero adaptados a la realidad, como son la importancia de agregar valor a través de la publicación de información interesante y relevante para los usuarios, útil y actualizada (Honigman, 2013; Manchetti, 2009), al igual que la necesidad de demostrar interés y compromiso a través de la participación en las conversaciones de los temas relacionados a la salud (Honigman, 2013; Manchetti, 2009), así como el seguir a otras organizaciones del mismo rubro y a otros líderes que se relacionen con el tema, además de a los usuarios que siguen a la cuenta (Honigman, 2013; Manchetti, 2009), también interactuar y contestar a los usuarios que responden lo tuiteado (Manchetti, 2009) y por supuesto ampliar el alcance del contenido y categorizar la información a través de hashtags adecuados sobre temas de salud (Honigman, 2013).

Es decir, que para comunicar en Twitter se debe aportar un marco adaptado al contexto y a las necesidades de los públicos a los que se dirige y esto se debe acompañar de una continua conversación e interacción. 


\section{Metodología}

Para el estudio de lo realizado en el contexto del fomento de la donación de órganos por el Minsa y EsSalud en Twitter, y el análisis de las respuestas de los usuarios ante los mensajes de estas instituciones, se recurrió a la entrevista en profundidad, con el fin de recoger información sobre las particularidades del proceso desde la perspectiva de los involucrados dentro de las organizaciones, así como a la técnica del análisis de contenido, por el aporte objetivo que esta permitiría obtener de la realidad, en el mismo escenario donde se desarrolla el proceso.

Considerando la importancia de obtener información de fuentes directas que aporten a la contextualización de la investigación, se entrevistó a miembros de la Organización Nacional de Trasplante (ONDT) y de la Gerencia de Procura y Trasplante de EsSalud, y para conocer todo lo relativo a la gestión de la comunicación realizada por estas instituciones en las redes sociales se recurrió a las personas encargadas de las áreas implicadas. Las personas entrevistadas fueron:

- Organización Nacional de Donación y Trasplante: Wendy Pujaico, Encargada de comunicación; Claudia Rodríguez, Bióloga responsable del Registro de Médula Ósea y Yeny Guerra Salas, Médico responsable de gestión (noviembre de 2015).

- Minsa: Mónica Yupanqui, Coordinadora de Comunicación Digital (mayo de 2016).

- EsSalud: Dr. Níquen Carvallo, Gerente de Procura y Trasplante (mayo de 2016) y Luisa Morcos, Subgerente de Redes sociales y Medios Audiovisuales (diciembre de 2015/mayo de 2016).

Con el fin de estudiar lo publicado por las dos instituciones, y realizar inferencias derivadas de datos cualitativos y cuantitativos, se empleó la técnica del análisis de contenido (Berelson, 1952: 18; Krippendorff, 2002: 28), indagando a partir de una matriz que establecía categorías en las publicaciones de cada una de las cuentas oficiales en Twitter, desde el inicio de las actividades de cada una (Minsa inicia en el año 2010 y EsSalud en el año 2012).

El muestreo de tweets fue no probabilístico e intencional (Alaminos, 2006: 50) y la muestra se consiguió a través del buscador avanzado de Twitter, en donde a partir del empleo de las palabras clave "órgano" y "órganos", se pudo obtener un listado en el que específicamente se mencione el tema, evitando así que se filtren otros mensajes. Una vez consultado este listado se procedió a analizar únicamente aquellos tweets donde se hiciera referencia directa al tema, quedando como resultado final lo siguiente:

EsSalud (@EsSaludPeru): 225 tweets (desde 2012 hasta julio de 2016).

Minsa (@Minsa_Peru): 108 tweets (desde 2010 hasta julio de 2016). 
La muestra de respuestas se desprendió de los tweets analizados anteriormente. Para seleccionar esta muestra únicamente se consideraron las respuestas que se referían al tema de la donación de órganos, quedando establecido lo siguiente: Minsa 30 respuestas y EsSalud 105 respuestas.

\section{Resultados}

\subsection{La comunicación en Twitter en el contexto del fomento de la donación de órganos}

Con el objetivo de fomentar la donación de órganos tanto desde el Minsa como desde EsSalud, se realizan diversas campañas a lo largo del año. La ONDT (que depende del Minsa) realiza varias actividades, como caminatas y conciertos, centrándose además en las campañas directas, en las cuales miembros de esta organización visitan centros comerciales, instituciones educativas o empresas, para informar e inscribir a personas que quieran formar parte de la lista de posibles donantes a través del acta de consentimiento voluntario.

En EsSalud, por su parte, existe una Semana del Donante de Órganos que se celebra en el mes de septiembre de cada año, en la cual se realizan actividades en todo el país, en las que participan los representantes de la institución y en especial los miembros de la Gerencia de Procura y trasplante, esa semana también se aprovecha en divulgar el tema en programas de radio y televisión. Estas actividades hacen que, durante esa semana, el tema de la donación sea tratado en todos sus medios de comunicación, donde se incluyen también a las redes sociales. Esta última institución ha realizado a su vez convenios con medios masivos (radio, televisión y prensa) para realizar campañas publicitarias sobre donación de órganos y de igual manera organiza un concurso anual para los periodistas, a través de sus publicaciones fomenten la donación de órganos (Premio Periodístico "Augusto Hernández Mendoza”).

Es importante mencionar que el Día del Donante de Órganos y Tejidos en el Perú (23 de mayo), es también una fecha clave, ya que las dos instituciones aprovechan para realizar diversas actividades para el fomento de la donación de órganos.

Ya en el escenario digital, ambas instituciones cuentan con un área dedicada a la comunicación en este entorno, y es allí donde se gestionan los medios sociales. Estas áreas dependen en ambos casos de otras de mayor jerarquía.

Tanto el Minsa como EsSalud tienen portales web institucionales, así como cuentas y páginas oficiales en redes sociales, además, en el contexto del fomento a la donación de órganos, cuentan con sitios alojados en estos portales, como es el caso del portal de la ONDT en la web del Minsa y de la Gerencia de Procura y Trasplante de EsSalud también en el portal institucional, así como el microsite "Yo dono un retweet" que forma parte de las acciones de esta última institución para el fomento de la donación de órganos en el escenario digital.

En la siguiente tabla se resumen los detalles sobre la comunicación digital de las organizaciones en el contexto del fomento de la donación de órganos. 
Tabla 1. Resumen sobre la comunicación digital en el Minsa y EsSalud.

\begin{tabular}{|c|c|c|}
\hline & Minsa & EsSalud \\
\hline Denominación del área & $\begin{array}{l}\text { Área de Comunicación } \\
\text { Digital }\end{array}$ & $\begin{array}{l}\text { Subgerencia de } \\
\text { Comunicaciones } \\
\text { Audiovisuales y Redes } \\
\text { Sociales }\end{array}$ \\
\hline Reporta a & $\begin{array}{l}\text { Oficina General de } \\
\text { Comunicaciones }\end{array}$ & $\begin{array}{l}\text { Oficina de Relaciones } \\
\text { institucionales }\end{array}$ \\
\hline Portal institucional & www.minsa.gob.pe & www.essalud.gob.pe \\
\hline Presencia en redes sociales ${ }^{1}$ & $\begin{array}{l}\text { Facebook, Twitter, } \\
\text { Youtube, Flickr }\end{array}$ & $\begin{array}{l}\text { Facebook, Twitter, Youtube, } \\
\text { Flickr }\end{array}$ \\
\hline $\begin{array}{l}\text { Canales digitales sobre } \\
\text { donación de órganos }\end{array}$ & $\begin{array}{l}\text { ONDT: http://www.minsa. } \\
\text { gob.pe/ondt/ }\end{array}$ & $\begin{array}{l}\text { Gerencia de Procura y } \\
\text { trasplante: https://ww1. } \\
\text { essalud.gob.pe/trasplanteweb/ } \\
\text { jsp/index.jsp } \\
\text { Campaña Dona un Retweet: } \\
\text { http://www.essalud.gob.pe/ } \\
\text { dona_un_retweet/ } \\
\text { Twitter Campaña Dona } \\
\text { un RT: https://twitter.com/ } \\
\text { YodonounRT }\end{array}$ \\
\hline $\begin{array}{l}\text { Seguidores en Twitter } \\
\text { (diciembre de 2016) }\end{array}$ & $\begin{array}{l}40.751 \\
\text { URL: https://twitter.com/ } \\
\text { minsa_peru }\end{array}$ & $\begin{array}{l}264.205 \\
\text { URL: https://twitter.com/ } \\
\text { EsSaludPeru }\end{array}$ \\
\hline
\end{tabular}

Fuente: Elaboración propia.

\subsection{Publicaciones sobre donación de órganos en Twitter}

El Minsa, desde su cuenta de Twitter publica principalmente información sobre procedimientos y estadísticas sobre la donación de órganos y también sobre las diversas actividades y eventos que se realizan con ese fin, así como sobre el Día del Donante de Órganos, además a través de sus tweets se insta a los usuarios a inscribirse como donantes.

En el caso de EsSalud, la mayoría de las publicaciones también fueron sobre procedimientos técnicos referentes al proceso de donación y trasplante de órganos, estadísticas sobre estos temas y actividades realizadas en el marco de las campañas, como apariciones en prensa, actividades en la Semana del Donante de Órganos y del Día Nacional del Donante de órganos y tejidos. Un importante porcentaje de tweets también tenía el objeto de sensibilizar con respecto a la importancia de la donación de órganos, y en otros casos se invitaba a registrarse como donantes y a apoyar las distintas campañas.

Un tema que se destaca en las publicaciones y en el cual EsSalud hace mayor énfasis, es en el de la importancia de que aquel que haya decidido inscribirse como donante de órganos, dialogue con su familia sobre la decisión. Esto se relaciona 
directamente con el problema explicado al principio, donde un obstáculo para la donación es la negativa de las familias de los potenciales donantes.

Otro aspecto destacable es que un gran porcentaje de las publicaciones de ambas instituciones están estrechamente vinculadas a las acciones de comunicación offline, ya que se emplea esta red social para informar sobre las actividades y hacer el minuto a minuto, y en el marco del contexto digital se utiliza para para complementar o reforzar información que se encuentra en otro sitio web o en otras redes sociales como Facebook.

El siguiente gráfico expone los temas que fueron tratados en los tweets analizados, en algunos casos fueron señalados en combinación, en una sola publicación.

Gráfico 1. Temas de las publicaciones sobre donación de órganos, Minsa y EsSalud.

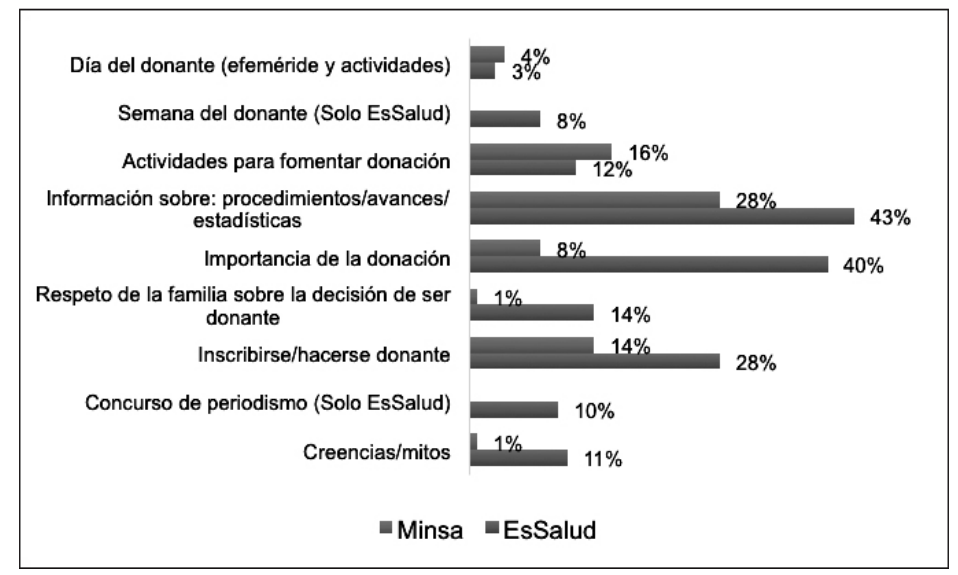

Fuente: Elaboración propia.

Se puede apreciar que también se tocaron puntualmente los temas que representan los factores mencionados entre los que podrían estar incidiendo negativamente en este acto, como son las creencias erróneas y mitos, así como la negativa de los familiares.

La evolución en el tiempo de las publicaciones de la muestra seleccionada se expone en la siguiente tabla.

Tabla 2. Distribución de las publicaciones analizadas.

\begin{tabular}{|c|c|c|}
\hline Años & Minsa & EsSalud \\
\hline 2010 & 10 & - \\
\hline 2011 & 15 & - \\
\hline 2012 & 20 & 8 \\
\hline 2013 & 25 & 18 \\
\hline 2014 & 17 & 40 \\
\hline 2015 & 11 & 106 \\
\hline 2016 (hasta julio) & 10 & 53 \\
\hline
\end{tabular}

Fuente: Elaboración propia. 
Se aprecia cómo en el Minsa se ha mantenido una tendencia y como en EsSalud, la mayor cantidad de publicaciones que mencionaba específicamente la donación y trasplante de "órganos" (lo que se pudo filtrar gracias a los descriptores de búsqueda), se han dado entre los años 2015 y 2016. También se evidencia que ha habido mayor actividad en el caso de EsSalud.

\subsection{Interacción y alcance}

En las conversaciones que se desataron a raíz de los tweets sobre donación de órganos, en el caso de EsSalud, se identificaron 11 intervenciones en torno al tema en cuestión y también sobre otros temas requeridos por los usuarios, mientras que en el caso del Minsa no se identificó ninguna intervención. Es así que, al confrontar la cantidad de comentarios de los usuarios sobre el tema y las intervenciones de las cuentas (Minsa 30 respuestas de usuarios sobre donación de órganos y ninguna intervención; EsSalud 105 respuestas y 11 intervenciones de la cuenta), se evidenció que no hubo reciprocidad en la comunicación.

Con respecto al alcance de las publicaciones, en el caso de EsSalud, los tweets más viralizados (por cantidad de retweets), fueron los que estuvieron enmarcados en las campañas de los hashtags \#YOQUIERODONAR y \#SoyDonanteMiFamiliaLoSabe. La máxima cantidad de retweets fue de 65, en una publicación que incluía una infografía y empleaba el hashtag \#SoyDonanteMiFamiliaLoSabe.

Imagen 1. Tweet con más retweets, EsSalud.

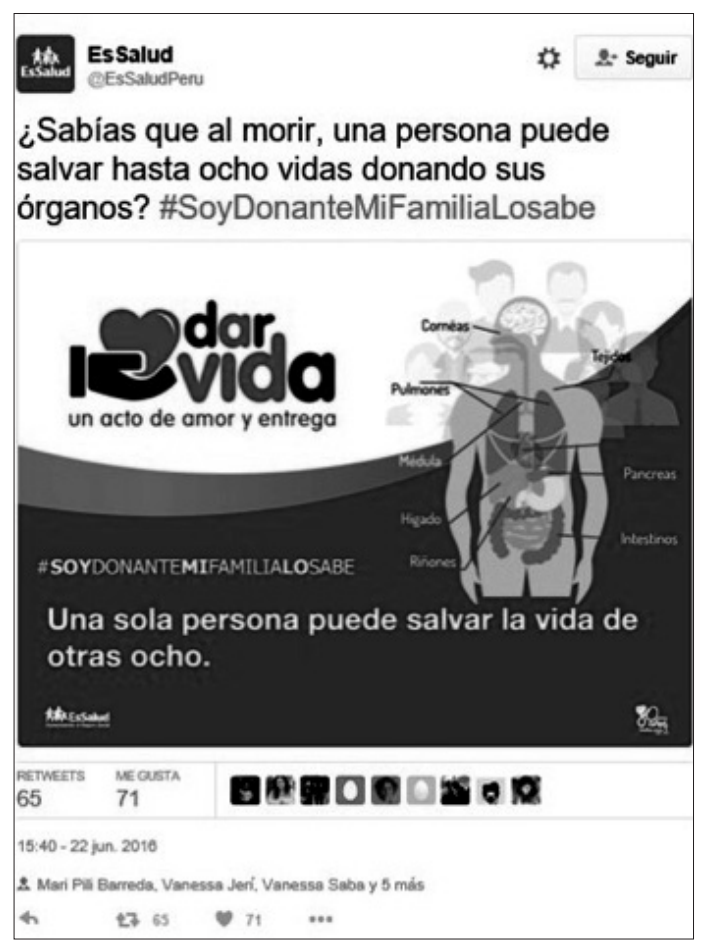

Fuente: Twitter EsSalud, https://twitter.com/EsSaludPeru/status/745718115204497409. 
En el Minsa, entre los tweets más viralizados se encontraron aquellos donde se anunciaba o publicaba el apoyo de personas conocidas a la donación de órganos y también aquellos con infografías, tal es así que la publicación con más retweets es una infografía que empleaba el hashtag \#PonSíentuDNI.

Imagen 2. Tweet con más retweets, Minsa.

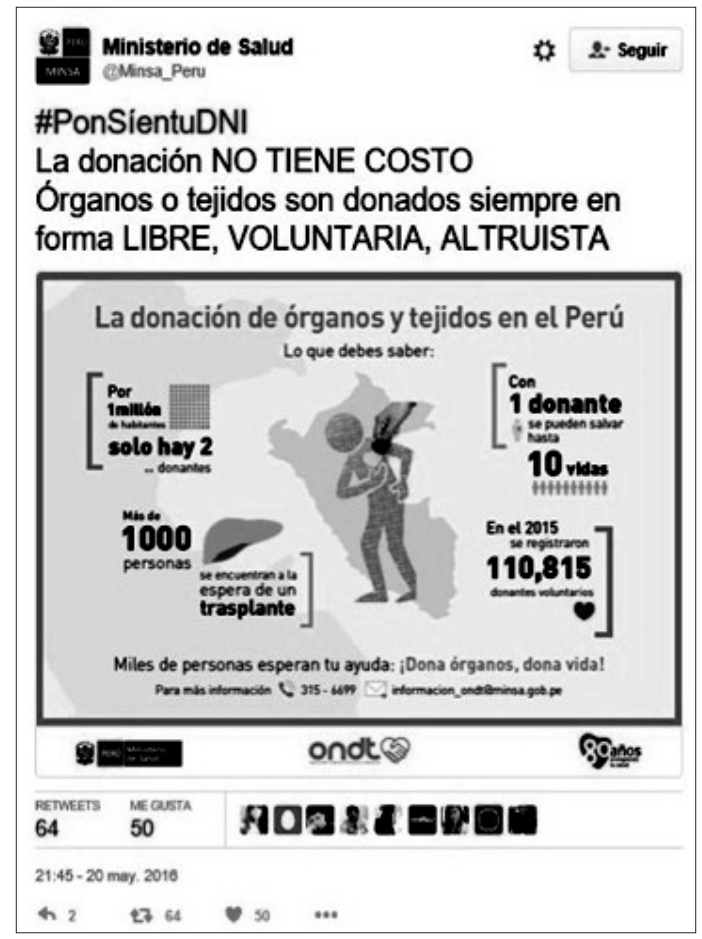

Fuente: Twitter Minsa, https://twitter.com/Minsa_Peru/status/733851245379739648.

\subsection{Elementos empleados para comunicar sobre donación de órganos en Twitter}

En este punto se clasifican los elementos que fueron identificados en cada caso, y para dimensionar los datos es importante volver a recordar que la muestra del Minsa estuvo conformada por 108 tweets y la de EsSalud por 225 tweets.

Datos e información: En ambos casos la mayoría de las publicaciones fueron informativas, lo cual se relaciona directamente con la necesidad de difundir información adecuada sobre el tema.

Hashtags: El hashtag es un recurso muy útil para agrupar y categorizar información y en las publicaciones del Minsa el $21 \%$ contenía uno o más hashtags. El más empleado fue \#PonSíentuDNI (2016), le sigue \#DonaciónDeÓrganos (2016) y \#DonaOrganos (2015 y 2016), mientras que en EsSalud el 49\% de las publicaciones analizadas empleaban este recurso, y entre los más mencionados figuran: \#EsSalud (2014, 2015 y 2016), \#SoyDonanteMiFamiliaLoSabe (2015 y 2016) y \#YOQUIERODONAR (2014). 
Imágenes y vídeos: El 32\% de los tweets del Minsa contenía imágenes, y en la muestra analizada solo se pudo identificar una publicación con vídeo. Se emplearon varias infografías, en especial en las publicaciones de 2016.

El 70\% de los tweets de EsSalud contenía vídeos o imágenes (64\% imágenes y $6 \%$ vídeos). Los vídeos se clasificaron en informativos, institucionales y testimoniales, las imágenes eran en su mayoría informativas e institucionales. El empleo de infografías fue bastante importante.

Enlaces: En el caso del Minsa se incluyeron enlaces en el 60\% de las publicaciones y EsSalud en el 23\%. En ambos casos, la mayoría de estos vínculos enlazaba a notas informativas sobre la donación de órganos en el portal web de la institución o en medios de comunicación.

Testimonios: En la muestra analizada del Minsa no se identificaron testimonios, pero en el caso de EsSalud el 15\% de la muestra estuvo conformada por testimonios (citas directas), de trasplantados, donantes, familiares de los mismos, así como médicos y autoridades de la institución que brindaban declaraciones sobre la donación de órganos.

Apoyo de líderes sociales: En las publicaciones del Minsa, esto se evidenció en tweets con enlaces y fotos mencionando el apoyo de personas públicas, especialmente artistas y periodistas. Se recurrió a este tipo de estrategia mínimamente si se compara con EsSalud.

Los tweets de EsSalud incluidos en esta categoría contenían fotos de artistas, periodistas, deportistas y políticos con el material de promoción de las diversas campañas realizadas. En el año 2014 este fue un elemento bastante utilizado, ya que una gran cantidad de tweets se basó en presentar el apoyo de estos líderes. En este contexto es importante destacar que cuando el protagonista del tweet era una persona conocida, las respuestas en su mayoría no se relacionaban al tema de la donación de órganos, sino al personaje.

Etiquetado: En ambos casos se etiquetó en imágenes a líderes de opinión, medios de comunicación y a otras instituciones públicas.

Llamado a la acción: Es importante determinar que se consideró como un llamado a la acción a aquellos tweets que instaban a realizar acciones específicas y que a su vez otorgaban los recursos (enlaces, directrices) para que el usuario automáticamente realice esa acción en el marco del entorno web.

En el caso del Minsa no se identificó ninguna publicación que reuniera estas características, mientras que en EsSalud el $4 \%$ de los tweets se podría enmarcar en un llamado a la acción, ya que instaban a comentar y a utilizar determinado hashtag o también se otorgaba el recurso para realizar una acción específica, como, por ejemplo, la invitación y el enlace para participar de un chat sobre donación de órganos a través de Facebook.

\subsection{Las creencias en la construcción de mensajes sobre donación de órganos}

Como se mencionó en la introducción, las creencias se constituyen como actores muy importantes en el contexto de la donación de órganos, y en la comunicación de las instituciones analizadas estas también estuvieron presentes. 
En el Minsa, del total de 108 tweets analizados, solo en tres se menciona una creencia, que es la compra y tráfico de órganos, una práctica que en el Perú no está permitida y que va en contra de lo estipulado en la Ley general de Donación y Trasplante de órganos (Congreso de la República del Perú, 2009).

En EsSalud se realizó toda una campaña sobre los mitos acerca de la donación de órganos en el año 2015, es por ello que de los 225 tweets publicados que conformaron la muestra, veinticuatro se refieren a los mitos o creencias. Entre estos, diez se limitan a mencionar la existencia de mitos, sin especificar cuáles, y en catorce publicaciones sí se especifican creencias y se aclaran aquellas que resultan ser erróneas.

Entre las creencias sobre donación mencionadas por el Minsa y EsSalud en Twitter, según la muestra analizada, se encuentran los temas indicados en la siguiente tabla.

Tabla 3. Creencias mencionadas en los tweets.

\begin{tabular}{|l|c|c|}
\hline Creencias & Minsa & EsSalud \\
\hline Secuestro de niños y personas para extraerles sus órganos & - & 4 \\
\hline Tráfico y comercio de órganos & 3 \\
\hline $\begin{array}{l}\text { Preferencia en acceso a la donación: Acceso a donación y trasplante de } \\
\text { óganos solo a personas conocidas, poderosas o ricas y las personas } \\
\text { de escasos recursos no tienen acceso a la donación y trasplante. }\end{array}$ & 3 \\
\hline $\begin{array}{l}\text { Dejan morir para extraer órganos: A las personas que sufren } \\
\text { accidentes se les dejará morir para extraerles sus órganos. En } \\
\text { este caso no especifican si se refieren a que esto sucede en los } \\
\text { establecimientos de salud. }\end{array}$ & 2 \\
\hline $\begin{array}{l}\text { La edad avanzada como factor que impide donar órganos: Sobre la } \\
\text { relevancia de la edad para ser donante. }\end{array}$ & - \\
\hline Personas que estaban muertas resucitaron & - & 1 \\
\hline Solo menciona "mitos" & - & 10 \\
\hline Total & $\mathbf{3}$ & $\mathbf{2 4}$ \\
\hline
\end{tabular}

Fuente: Elaboración propia.

Teniendo en cuenta estos datos, se evidencia que EsSalud hizo mucho mayor énfasis en poner en la agenda pública a los mitos y creencias, mientras que en la muestra del Minsa esto no tuvo mucha relevancia.

\subsection{Respuestas de los usuarios ante los mensajes sobre donación de órganos en Twitter}

Como se explicó al principio, Twitter también se ha convertido en una ventana que permite reconocer aquello que los usuarios saben, creen y perciben acerca de temas de salud, y en el contexto analizado se han identificado los aspectos que se explican a continuación: 
- Las respuestas a los tweets de ambas instituciones sobre donación de rganos fueron mayormente positivas con respecto al tema.

- Los comentarios positivos estuvieron conformados en su mayoría por las afirmaciones de usuarios sobre el deseo de inscribirse como donantes o de que ya eran donantes, mientras que los negativos se relacionaban con creencias o mitos.

- Algunos usuarios demuestran con sus respuestas que aún existen creencias erróneas y mitos sobre la donación de órganos, las respuestas con carga negativa son precisamente las relacionadas a estos temas.

En el caso del Minsa, se mencionaron creencias o mitos en cuatro respuestas, tres hacían referencia al tráfico de órganos y en una también se mencionaba a los médicos en el contexto de esta práctica.

Estableciendo una relación entre los mensajes del Minsa (108) y las respuestas recibidas (30), resalta que esta institución no hizo mucho énfasis en el tema de mitos y creencias y esto también pudo haber repercutido en la cantidad respuestas y en el debate que se generó.

De la muestra total seleccionada de publicaciones sobre donación de órganos en EsSalud (225), un total de 65 tweets tuvieron una respuesta de los usuarios sobre el tema en cuestión, haciendo en total 105 respuestas sobre donación de órganos, de las cuales 17 mencionaban creencias, estas respuestas se dieron principalmente en las publicaciones donde se aludía a estos temas, donde cinco mencionaban "mitos" en general, sin especificar, y doce mencionaban los distintos temas que se exponen a continuación.

Tabla 4. Creencias de usuarios.

\begin{tabular}{|l|l|l|}
\hline Creencias & Minsa & EsSalud \\
\hline $\begin{array}{l}\text { Tráfico y comercio de órganos/La existencia de mafias que trafi- } \\
\text { can órganos }\end{array}$ & 3 & 4 \\
Tráfico y comercio de órganos/Personal de salud y tráfico de órganos & 1 & 2 \\
$\begin{array}{l}\text { Secuestros para robar órganos } \\
\text { Si uno va al hospital lo dejarán morir para extraer sus órganos }\end{array}$ & - & 2 \\
$\begin{array}{l}\text { Preferencia para acceso a donación } \\
\text { Grupo religioso que no deja donar órganos a sus fieles (Testigos } \\
\text { de Jehová) }\end{array}$ & - & 2 \\
Solo menciona "mitos" & 1 & 1 \\
\hline Total & $\mathbf{5}$ & $\mathbf{1 7}$ \\
\hline
\end{tabular}

Fuente: Elaboración propia.

Lo que se puede evidenciar en estos resultados es que aparecen algunos tópicos que, en la muestra analizada de mensajes publicados por las instituciones, no fueron 
mencionados, como, por ejemplo, la creencia de la relación de los médicos con el tráfico de órganos y la creencia sobre la existencia de mafias, temas que sí se mencionan en algunas de las respuestas analizadas.

\section{Conclusiones}

Se pudo identificar que ambas instituciones consideran algunos de los aspectos mencionados entre las buenas prácticas en Twitter por Herrera y Requejo (2012), y más específicamente en el contexto de la salud por Honigman (2013) y Manchetti (2009), ya que a través de los elementos empleados en las publicaciones se agrega valor mediante el aporte de bastante información y datos sobre la donación de órganos, mediante el empleo de imágenes, infografías y vídeos, para reforzar los mensajes, aspecto en el que EsSalud hizo mayor énfasis.

Sin embargo, el aspecto relacional, que debería estar marcado por la conversación propiciada por estas instituciones en Twitter, no está muy desarrollado, ya que según lo analizado, la comunicación se caracteriza por tener un marcado carácter unidireccional, a pesar de ser esta una plataforma donde por sus características se debería propiciar el relacionamiento, enmarcado esto último además en un intercambio de información de ida y vuelta, una de las características de la comunicación en salud planteada por Schiavo (2007).

Sobre la reducida actividad del Minsa, de acuerdo a la muestra, se puede deber a las características de esta institución, ya que el proceso para desarrollar iniciativas debe pasar por diversas aprobaciones y además se tiene una agenda marcada por el calendario de la OMS y por los acontecimientos coyunturales, esto quiere decir que ante alertas sanitarias, ellos enfocan sus fuerzas en comunicar sobre un problema latente en determinado momento (M. Yupanqui, comunicación personal, 11 de mayo de 2016), y hay que considerar también que esta institución tiene un alcance muy amplio, lo que hace que deba repartir sus esfuerzos entre una multitud de temas.

En el caso de EsSalud, aunque también las acciones deben ser consensuadas entre las diferentes unidades de la Oficina de Relaciones Institucionales, se realizan acciones en articulación con otras áreas y en el marco de campañas institucionales, a partir de las iniciativas e información de la Gerencia de Procura y Trasplante (L. Morcos, comunicación personal, 23 de diciembre de 2015), lo que pudo propiciar que exista mayor tratamiento del tema.

Es por ello que el principal aspecto por reforzar en ambos casos es el relacional, ya que las respuestas a los usuarios han sido mínimas, lo que los mismos podrían percibir como una falta de interés real de las organizaciones (Manchetti, 2009) sobre el tema que ponen en agenda.

Después del análisis se identificaron también algunos criterios que podrían considerarse al diseñar estrategias de comunicación en salud a través de esta red social, como que una comunicación continua en el tiempo sobre determinado tema permite conseguir valiosa retroalimentación por parte de los usuarios y también que al tocar ciertos tópicos sensibles y presentar casos reales (testimonios), se abre la puerta para que se establezcan debates con respecto a temas de salud.

Teniendo en cuenta todo lo anterior, se podría considerar a Twitter como un espacio ideal para que las instituciones reciban retroalimentación, lo que a su vez 
ayudaría a desarrollar estrategias que logren influir en la actitud de las personas con respecto a la donación de órganos, consiguiendo así que esto repercuta positivamente en la tasa de trasplantes, lo que impactaría a su vez en la mejora de la salud de muchas personas.

\section{Referencias bibliográficas}

Alaminos, A. (2006). El muestreo en la investigación social. En Alaminos, A. \& Castejón Costa, J. Elaboración, análisis e interpretación de encuestas, cuestionarios y escalas de opinión. Alicante: Vicerrectorado de Calidad y Armonización Europea, Instituto de Ciencias de la Educación, Universidad de Alicante. Recuperado de https://rua.ua.es/dspace/bitstream/10045/20331/1/Elaboraci\%C3\%B3n,\%20 an\%C3\%A1lisis\%20e\%20interpretaci\%C3\%B3n.pdf

Alcalay, R. (1999). La comunicación para la salud como disciplina en las universidades estadounidenses. Revista Panamericana de Salud Pública, 5(3), 192-196. doi: http://dx.doi.org/10.1590/S1020-49891999000300020

Berelson, B. (1952). Content Analysis in Comunication Research. Glencoe: Free Press. Berry, D. (2007). Health Communication: Theory and Practice. (Payne, S. y Horn, S. Ed.) Berkshire: Open University Press, McGraw-Hill Education

Caballero Uribe, C. (2011). La Web 2.0, Salud 2.0 y el futuro de la Medicina. Salud Uninorte, 27(2), vii-X. Recuperado de http://www.scielo.org.co/pdf/sun/v27n2/v27n2a02.pdf

Chew, C. y Eysenbach, G. (2010). Pandemics in the Age of Twitter: Content Analysis of Tweets during the 2009 H1N1 Outbreak. Plos One, 5(11), e14118. doi: http://dx.doi.org/10.1371/journal.pone.0014118

Congreso de la República del Perú (11 de diciembre de 2009). Ley que promueve la obtención, la donación y el trasplante de órganos o tejidos humanos (Ley $\mathrm{N}^{\mathrm{o}}$ 29471). Recuperado de http://www.minsa.gob.pe/ondt/normas/Ley_29471.pdf

Congreso de la República del Perú (7 de junio de 2000). Ley de fomento de la donación de órganos y tejidos humanos (Ley $\mathrm{N}^{\circ}$ 27282). Recuperado de ftp://ftp. minsa.gob.pe/intranet/leyes/L27282_DOT.pdf

Congreso de la República del Perú (7 de junio de 2016). Ley que modifica los artículos 2, 3 y 4, y la disposición complementaria única de la Ley 29471, Ley que promueve la obtención, la donación y el trasplante de órganos o tejidos humanos (Ley N $\mathrm{N}^{\mathrm{3}}$ 30473). Recuperado de http://www.elperuano.com.pe/NormasElperuano/2016/06/29/1398360-1.html

Council of Europe y Organización Nacional de Trasplantes (2012). Newsletter Transplant. Vol. 17. Recuperado de http://www.transplant-observatory.org/download/ newsletter-transplant-2012/.

Council of Europe y Organización Nacional de Trasplantes (2013). Newsletter Transplant. Vol. 18. Recuperado de http://www.ont.es/publicaciones/Documents/ newsletter_transplant_vol_18_no_1_september_2013.pdf 
Council of Europe y Organización Nacional de Trasplantes (2014). Newsletter Transplant. Vol. 19. Recuperado de http://www.transplant-observatory.org/download/ newsletter-transplant-2014/

Council of Europe y Organización Nacional de Trasplantes (2015). Newsletter Transplant. Vol. 20. Recuperado de https://www.edqm.eu/sites/default/files/ newsletter_transplant_2015.pdf

Council of Europe y Organización Nacional de Trasplantes (2016). Newsletter Transplant. Vol. 21. Recuperado de https://www.edqm.eu/sites/default/files/ newsletter_transplant_volume_21_september_2016.pdf

Cuesta Cambria, U., Menéndez Hevia, T., \& García Guardia, M. (2008). Comunicación social y salud: Un nuevo planteamiento estratégico. En Cuesta Cambria, U., Ugarte Iturrizaga, A. \& Menéndez Hevia, T. (Coord.), Comunicación y salud: avances en modelos y estrategias de intervención (p.p. 19-38). Madrid: Editorial Complutense. Recuperado de http://www.fundadeps.org/recursos/documentos/268/cys-avances-ecomplutense-2008.pdf

Culotta, A. (2010). Towards detecting influenza epidemics by analyzing Twitter messages. Proceedings Of The First Workshop On Social Media Analytics - SOMA '10., 115-122. doi: http://dx.doi.org/10.1145/1964858.1964874

Curioso, W. \& Carnero, A. (2011). Promoviendo la investigación en salud con Twitter. Revista Médica Herediana, 22(3), 121-130. doi: http://dx.doi.org/10.20453/rmh.v22i3.1086

Gore, R., Diallo, S., \& Padilla, J. (2015). You Are What You Tweet: Connecting the Geographic Variation in America's Obesity Rate to Twitter Content. Plos One, 10(9), e0133505. doi: 10.1371/ journal.pone.0133505

Herrera, S. \& Requejo, J. (2012). 10 Good Practices for News Organizations Using Twitter. Journal Of Applied Journalism \& Media Studies, 1(1), 79-95. doi: http:// dx.doi.org/10.1386/ajms.1.1.79_1

Honigman, B. (2013). How to Use Twitter for Healthcare Effectively (4 Tips). Recuperado de https://getreferralmd.com/2013/12/twitter-health-care/

Instituto Nacional de Estadística e Informática (INEI) (2014). Población que accede a Internet. Recuperado de https://www.inei.gob.pe/estadisticas/indice-tematico/ population-access-to-internet

Kotskova, P. (2015). Public health. En Macy, M., Mejova, Y., \& Weber, I. (Ed.). Twitter: A digital socioscope. New York: Cambrige University Press

Kreps, G. (2012). The Maturation of Health Communication Inquiry: Directions for Future Development and Growth. Journal Of Health Communication, 17(5), 495-497. http://dx.doi.org/10.1080/10810730.2012.685802

Krippendorff, K (2002). Metodología de análisis de contenido. Teoría y Práctica. Barcelona: Editorial Paidós Comunicación.

Manchetti, S. (agosto de 2009). Twitter Best Practices For Health Communicators. Presentación en National Conference for Health Communication, Marketing and Media. Recuperado de http://es.slideshare.net/socialogilvy/ twitter-best-practices-for-health-communicators

Matesanz, R (1994). Tráfico de órganos: hechos, ficciones y rumores. Nefrología, XIV(6), 633-645. Recuperado de http://www.revistanefrologia.com/ es-publicacion-nefrologia-articulo-trafico-organos-hechos-ficciones-rumores-X0211699594007012 
Ministerio de Salud del Perú (Minsa). (23 de mayo de 2015). A la fecha 108 mil personas han expresado su voluntad de donar sus órganos. Recuperado de http:// www.minsa.gob.pe/?op $=51 \&$ nota $=17367$

Ministerio de Salud del Perú (Minsa). (26 de marzo de 2016). Gracias a que recibió donación de órganos hace 6 años trabajadora del Minsa pudo ser madre. Recuperado de http://www.minsa.gob.pe/?op=51\&nota $=17367$

Neciosup, V.H. (4 de noviembre de 2014). Donación y trasplante de órganos en el Perú. (Informe de investigación 83/2014-2015). Perú: Congreso de la República. Recuperado de http://nubr.co/KQJBVA

Neuhauser, L. \& Kreps, G. (2010). eHealth communication and behavior change: promise and performance. Social Semiotics, 20(1), 9-27. doi: http://dx.doi. org/10.1080/10350330903438386

Nutbeam, D. (1998). Promoción de la salud. Glosario. Ginebra: Organización Mundial de la Salud. Recuperado de http://apps.who.int/iris/bitstream/10665/67246/1/ WHO_HPR_HEP_98.1_spa.pdf

O'Reilly, T. (2005). What Is Web 2.0. Design Patterns and Business Models for the Next Generation of Software. Recuperado de http://www.oreilly.com/pub/a/ web2/archive/what-is-web-20.html

Organización Mundial de la Salud (OMS). Resoluciones y decisiones, Anexo. (2005). En 58 Asamblea Mundial de la Salud, 115. Ginebra, Suiza. Recuperado de http://apps.who.int/gb/ebwha/pdf_files/WHA58-REC1/A58_2005_ REC1-sp.pdf

Organización Nacional de Donación y Trasplante, Perú (ONDT). (s.f.). Todos podemos ser donantes. Recuperado de http://www.minsa.gob.pe/ondt/todos.html

Organización Nacional de Donación y Trasplante, Perú (ONDT). (s.f.). ¿Qué es la ONDT? Recuperado de http://www.minsa.gob.pe/ondt/quees.html

Organización Nacional de Trasplantes, España (ONT). (s.f.). Donación. Recuperado de: http://www.ont.es/informacion/Paginas/Donaci\%C3\%B3n.aspx

Paul, M. \& Dredze, M. (2011). You Are What You Tweet: Analyzing Twitter for Public Health. Presentado en Fifth International AAAI Conference on Weblogs and Social Media, 265 - 272. Recuperado de http://www.aaai.org/ocs/index.php/ ICWSM/ICWSM11/paper/view/2880/3264

Quantico Trends. (2016). Investiga a tus clientes y competidores en redes sociales. Recuperado de http://es.slideshare.net/QuanticoTrends

Ratzan, S. C..; Stearns, N. S.; Payne, J. G.; Amato, P. P. \& Liebergott, J. W. (1994). Education for the Health Communication profesional. A collaborative curricular partnership. American Behavioral Scientist, 38(2), 361-380. Recuperado de http://journals.sagepub.com/doi/pdf/10.1177/0002764294038002015

Scanfeld, D., Scanfeld, V., \& Larson, E. (2010). Dissemination of health information through social networks: Twitter and antibiotics. American Journal Of Infection Control, 38(3), 182-188. doi: http://dx.doi.org/10.1016/j. ajic.2009.11.004

Schiavo, Renata (2007). Health Communication: From Theory to Practice. San Francisco: Jhon Wiley \& Sons, Jossey-Bass

Seguro Social de Salud (EsSalud) (s.f.). Nuestra institución. Recuperado de http:// www.essalud.gob.pe/nuestra-institucion/\#tabs-5-0-0 
The Lima Consulting Group (2009). Estudio de opinión sobre la donación y trasplante de órganos. Resultados del Estudio Cuantitativo - Año 2009. Ministerio de Salud del Perú. Recuperado de http://nubr.co/XSIY80

Twitter Investor Relations (2017). Q4 2016 Letter to Shareholders. Recuperado de http://bit.ly/2nj9JnV

Wright, K. B., Sparks, L., \& O’Hair, H. D. (2013). Health communication in the 21st century. Oxford: Jhon Wiley \& Sons, Blackwell. 